\title{
MUCOEPIDERMOID CARCINOMA OF THE BREAST: A RARE CASE
}

\author{
Arun Kumar S. L1, A. L. Nagaraja2, Srinivasaiah M³, Lakkanna $S^{4}$ \\ 1 Junior Resident, Department of General Surgery, Employees' State Insurance Corporation Medical College and Post Graduate Institute \\ of Medical Sciences and Research. \\ 2Associate Professor, Department of General Surgery, Employees' State Insurance Corporation Medical College and Post Graduate \\ Institute of Medical Sciences and Research. \\ ${ }^{3}$ Assistant Professor, Department of General Surgery, Employees' State Insurance Corporation Medical College and Post Graduate \\ Institute of Medical Sciences and Research. \\ ${ }^{4}$ HOD \& Professor, Department of General Surgery, Employees' State Insurance Corporation Medical College and Post Graduate \\ Institute of Medical Sciences and Research.
}

\section{ABSTRACT}

Mucoepidermoid carcinoma of the salivary glands are common but it's a rare tumour in the breast. Only 28 cases have been reported in the literature. The patient presented with lump in the right breast of duration 6 months with FNAC showing fibrocystic disease but excisional biopsy showed low-grade mucoepidermoid carcinoma of the right breast. Later patient underwent right modified radical mastectomy and adjuvant chemoradiation and she is disease free after a follow-up of 2 years. There is less literature available on this about the management and prognosis.

\section{KEYWORDS}

MEC, Mucoepidermoid, Carcinoma Breast, Rare Case.

HOW TO CITE THIS ARTICLE: Arun Kumar SL, Nagaraja AL, Srinivasaiah M, et al. Mucoepidermoid carcinoma of the breast: a rare case. J. Evolution Med. Dent. Sci. 2016;5(15):739-740, DOI: 10.14260/jemds/2016/170

\section{INTRODUCTION}

Mucoepidermoid carcinoma is a rare type of cancer that is usually seen in the major salivary glands and may also occur in the breast, thyroid and lacrimal glands rarely. ${ }^{1}$ Breast mucoepidermoid carcinoma is a variant of breast carcinoma accounting for an incidence approximately 0.2 to $0.3 \%$ shows morphologically and immunohistochemical features similar to those of salivary glands. The carcinoma usually develops from basaloid, intermediate, epidermoid and mucinous cells. Tumours with high grade has poor prognosis while tumours with the low grade has better prognosis. ${ }^{2}$

\section{CASE REPORT}

A 34-year-old female presented to ESIC MC PGIMSR, Department of General Surgery, with history of painless lump in right breast of 6 months' duration and serosanguinous nipple discharge of 3 months' duration. On clinical examination, there was a lump of $4 * 5 \mathrm{~cm}$ in right upper outer quadrant with no axillary lymphadenopathy. Nipple discharge was negative for malignant cells. Patient underwent FNAC which showed fibrocystic disease. Histopathological examination showed low-grade mucoepidermoid carcinoma of the breast with ER and PR and HER2 negative. Subsequently, patient underwent right modified radical mastectomy with adjuvant chemoradiation, as her metastatic workup was normal. Patient is currently on tamoxifen with no recurrence after a follow-up of 2 years.

Financial or Other, Competing Interest: None.

Submission 10-01-2016, Peer Review 05-02-2016,

Acceptance 11-02-2016, Published 22-02-2016.

Corresponding Author:

Dr. Arun Kumar S. L,

Room No. B18, ESIC Men's Hostel,

ESIC MC, PGIMSR, Rajajinagar,

Bangalore-560010.

E-mail: arunsdumc006@gmail.com,arunmbbsms@gmail.com DOI: $10.14260 /$ jemds $/ 2016 / 170$

\section{DISCUSSION}

Mucoepidermoid carcinoma of the breast was first described in $1979 .{ }^{3}$ It is a rare type of breast carcinoma accounting for 0.2 to $0.3 \%$ of all breast carcinomas with only 28 cases have been reported in the literature till date.2,4 Breast and salivary glands are tubuloacinar exocrine glands arising from embryonal ectoderm can manifest as tumours of similar morphology.1,4 MEC of the breast has two variants, firstly lowgrade MEC and high-grade MEC. Both of them have intermediate, epidermoid and glandular cells. Low-grade MEC have epithelial cells that show keratinization and small lumen forming glandular cells, high-grade MEC have epidermoid and mucinous cells with focal necrosis. ${ }^{2}$

Immunohistochemically, MEC stains positive for cytokeratin (CK)-7, CK-5/6, CK-14, mucins (MUC), p53, Vascular Endothelial Growth Factor (VEGF) and Epidermal Growth Factor Receptor (EGFR). Tumor cells do not express hormonal receptors (neither estrogen nor progesterone) nor HER-2/neu protein. ${ }^{5}$

Clinical presentation is similar to other variants, but because of less literature available there is no clear management protocols for the entity at present. These are managed similar to other variants of carcinoma of the breast. ${ }^{5}$

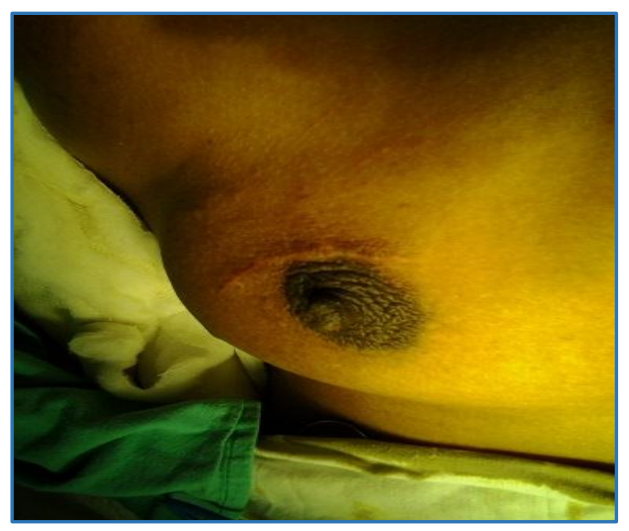

Image of right breast showing previous surgical scar of excisional biopsy in right upper outer quadrant 


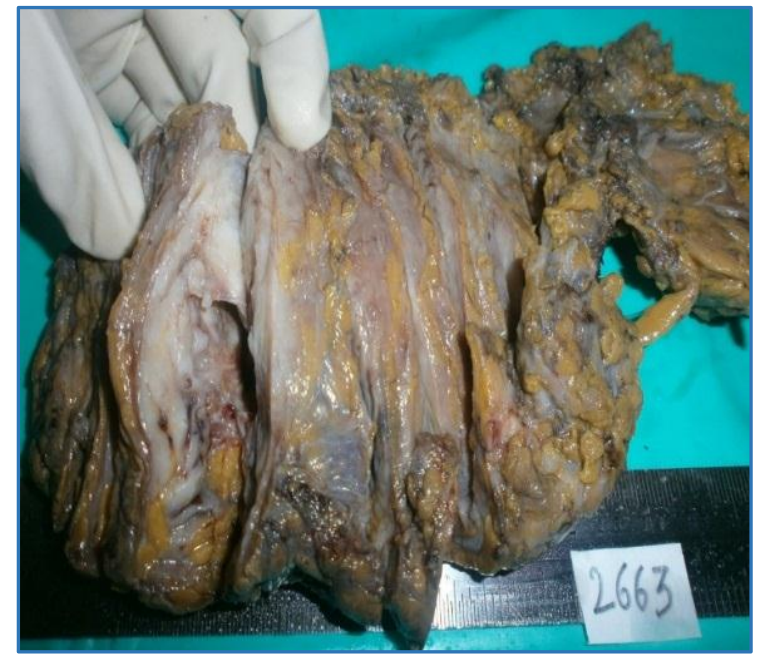

Gross Right MRM Specimen showing tumour excised cavity in the breast

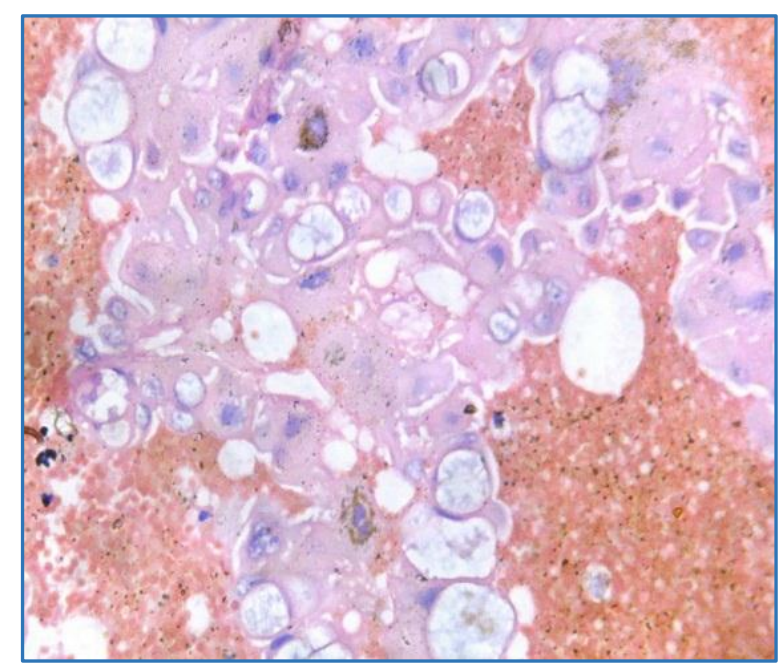

Microscopic-breast tissue with extensive fibrocystic changes amidst which is seen a neoplasm composed of multiple cystic spaces filled by proliferation of intermediate cells and squamous cells, some of the cysts are filled by mucous and partially lined by mucous producing cells. Features consistent with low-grade mucoepidermoid carcinoma of the breast.

\section{REFERENCES}

1. Pia-Foschini M, Reis-Filho JS, Eusebi V, et al. Salivary gland-like tumours of the breast: surgical and molecular pathology. J Clin Pathol 2003;56:497-506.

2. Sandra I Camelo-Piragua, MD; Claudine Habib, MD; Prathima Kanumuri MD, et al. Mucoepidermoid carcinoma of the breast shares cytogenetic abnormality with mucoepidermoid carcinoma of the salivary gland: a case report with molecular analysis and review of the literature. Human pathology 2008 Nov; 40:887-892.

3. Patchefsky AS, Frauenhoffer CM, Krall RA, et al. Lowgrade mucoepidermoid carcinoma of the breast. Arch Pathol Lab Med 1979;103:196-8.

4. Berry MG, Caldwell C, Carpenter R. Mucoepidermoid carcinoma of the breast: a case report and review of the literature. Euro Jour of Surg Onco 1998;241:78-80.

5. Murat Basbuga, Sami Akbuluta, Zulfu Arikanoglua, et al. Mucoepidermoid carcinoma in a breast affected by burn scars: comprehensive literature review and case report. Breast Care 2011;6:293-297. 